\title{
Erratum to: Derivation of netput shadow prices under different levels of pest pressure
}

\author{
Theodoros Skevas ${ }^{1} \cdot$ Teresa Serra $^{2}$
}

Published online: 20 July 2017

(C) Springer Science+Business Media, LLC 2017

\section{Erratum to: J Prod Anal (2017) DOI 10.1007/s11123-017-0507-5}

The original version of this article unfortunately contained a typo in Eq. 5a in Methodology section. A plus sign has been inadvertently added in the second line of the equation. The corrected equation is given below:

This has been corrected in the original version of the article.

The online version of the original article can be found at doi:10.1007/ s11123-017-0507-5.

Theodoros Skevas

skevast@missouri.edu

1 Department of Agricultural and Applied Economics, University of Missouri, 200 Mumford Hall, Columbia, MO 65211, USA

2 Department of Agricultural and Consumer Economics, University of Illinois, 335 Mumford Hall, 1301 W Gregory Drive, Urbana, IL 61801, USA

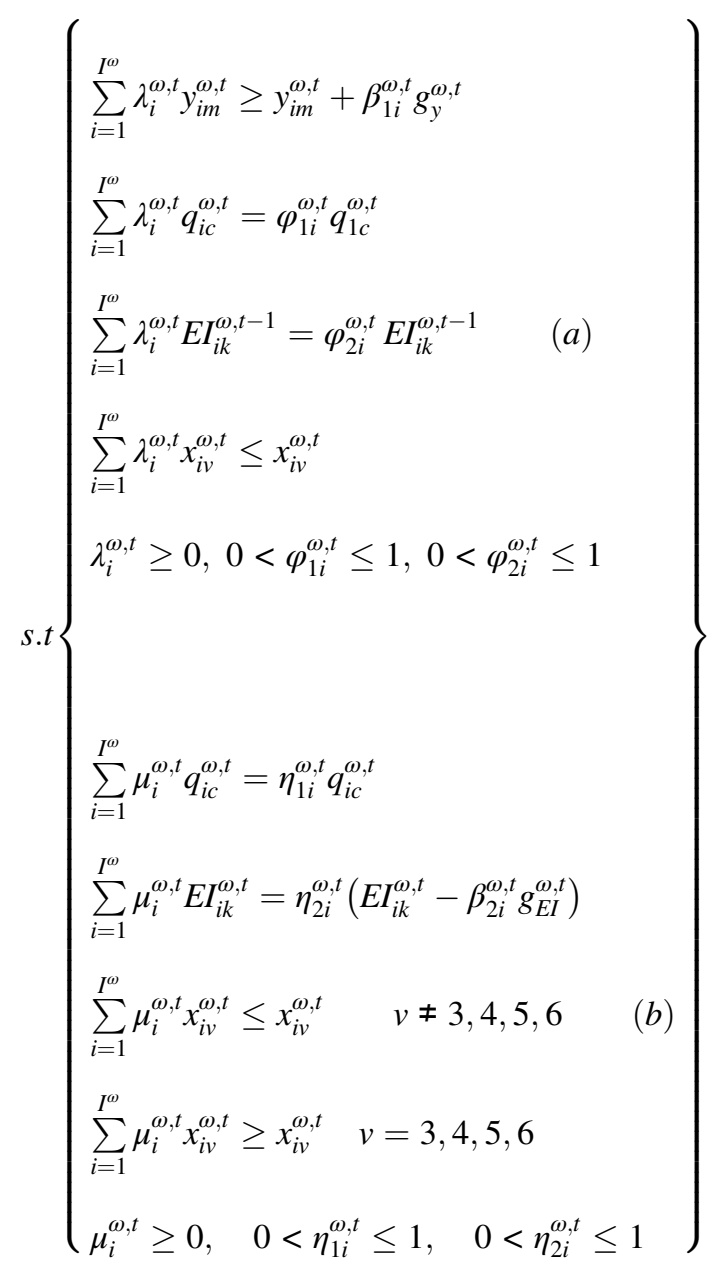

